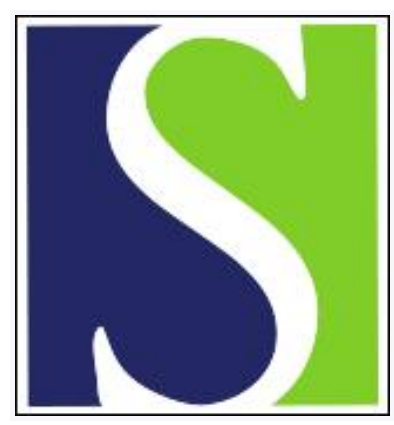

Scand J Work Environ Health 2007;33(2):153-159

https://doi.org/10.5271/sjweh.1120

Issue date: 31 Apr 2007

Occupational vocal cord dysfunction due to exposure to wood dust and xerographic toner

by Muñoz X, Roger A, De la Rosa D, Morell F, Cruz MJ

Affiliation: Servicio de Neumología, Hospital General Vall d'Hebron, Passeig Vall d'Hebron 119, ES-08035 Barcelona, Spain. xmunoz@vhebron.net

Refers to the following text of the Journal: 2005;31(3):224-226

Key terms: case report; exposure; iroko; occupational vocal cord dysfunction; rhinolaryngoscopy; specific inhalation challenge; stridor; western red cedar; xerographic toner

This article in PubMed: www.ncbi.nlm.nih.gov/pubmed/17460804

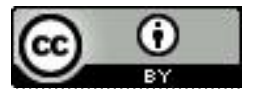




\title{
Occupational vocal cord dysfunction due to exposure to wood dust and xerographic toner
}

\author{
by Xavier Muñoz, PhD, ${ }^{1,2}$ Alex Roger, MD, ${ }^{1}$ David De la Rosa, MD, ${ }^{1}$ Ferran Morell, PhD, ${ }^{1}$ Maria J Cruz, \\ $P h D^{1}$
}

\begin{abstract}
Muñoz X, Roger A, De la Rosa D, Morell F, Cruz MJ. Occupational vocal cord dysfunction due to exposure to wood dust and xerographic toner. Scand J Work Environ Health 2007;33(2):153-158.
\end{abstract}

Objectives Vocal cord dysfunction is a poorly understood entity that is often misdiagnosed as asthma. Both irritant and nonirritant vocal cord dysfunction have been described. This report presents two cases of irritant vocal cord dysfunction secondary to specific environmental exposure, the first to iroko and western red cedar wood (a carpenter) and the second to xerographic printing toner (a secretary).

Methods Several tests were performed, including chest radiographs, measurements of total serum immunoglobulin E, skin prick tests with common pneumoallergens (as well as iroko and western red cedar in the first case), pulmonary function studies, methacholine challenge testing, specific inhalation challenge performed with suspected agents in a single-blinded fashion, and peak expiratory flow testing and fiberoptic rhinolaryngoscopy (in case 1).

Results During the specific inhalation challenge, the patients showed dysphonia, chest tightness, inspiratory stridor, and flattening of the inspiratory limb of the maximum flow-volume loop in spirometry, with no significant decreases in the level of forced expiratory volume in 1 second; fiberoptic rhinolaryngoscopy confirmed the diagnosis of vocal cord dysfunction in case 1.

Conclusions It is important to know that agents that can cause occupational asthma can also cause vocal cord dysfunction. The mechanisms by which these agents produce vocal cord dysfunction are unknown. The differences in the clinical presentation of the patients described relative to the reported cases suggest that more than one pathophysiological mechanism may be implicated in the genesis of this entity.

Key terms iroko; rhinolaryngoscopy; stridor; specific inhalation challenge; western red cedar.

Vocal cord dysfunction is a respiratory condition characterized by abnormal adduction of the vocal cords. It can lead to wheezing and shortness of breath during the respiratory cycle $(1,2)$. The diagnosis can be difficult because the symptoms are similar to those of asthma and because the condition can occur concomitantly with asthma $(3,4)$.

Vocal cord dysfunction has been associated with psychiatric factors, female gender, employment in health care (5), athletic activities (6-8), and, recently, exposure to irritants at work (9). Because vocal cord dysfunction often mimics asthma, it is essential to consider this diagnosis for symptomatic patients in order to distinguish it from reactive airway dysfunction syndrome (RADS) (9). The pathophysiology of irritant-induced vocal cord dysfunction remains unknown. One hypothesis is that olfactory nerve stimulation or direct stimulation of nociceptive sensory nerve endings in the upper and lower respiratory tract may initiate local reflex arcs or higher center processing that leads to paradoxical laryngeal closure during inspiration or expiration. After acute or chronic inhalational injury to the airways, there may be a change in the number or regulation of sensory nerve endings that somehow lowers the threshold for irritating the glottic closure reflex to protect the lower airways from noxious exposure (10).

The few reported cases to date would concur with the hypothesis that vocal cord dysfunction can be caused by any nonspecific irritant in persons predisposed to develop this syndrome $(9,10)$. Nevertheless, in the last 
2 years, two case reports have been published in which the patients developed vocal cord dysfunction following exposure to a specific irritant alone $(11,12)$.

In this report we describe two cases of vocal cord dysfunction secondary to exposure to specific environmental agents. The first, involving a carpenter, was related to iroko and red cedar wood, and the second, involving a secretary, was related to a xerographic toner. In addition, we discuss the fact that more than one ethiopathogenic mechanism can be implicated in the genesis of this syndrome.

\section{Clinical cases}

\section{Case 1}

The first case involved a 26-year-old man, a nonsmoker whose clinical history was unexceptional other than having been subject to anxiety-depression syndrome of 6 years' evolution that involved episodes of anxiety crises characterized by dyspnea, oppressive chest tightness, and sweating. He was being treated with paroxetine for this condition and had required several visits to a hospital emergency room, where the symptoms remitted following the administration of diazepam. For the last 6 years, he had been employed as a carpenter, carrying out several tasks, such as cutting, sanding, and gluing wood. He generally worked with beech and pine, but in the last year he had begun using iroko and western red cedar wood.

The patient was referred to our department for examination in respect to two episodes of sudden dysphonia, dry cough, and progressive dyspnea with inspiratory wheezing, which had occurred in the previous 15 days while he worked with iroko and western red cedar. The episodes required emergency-room assistance and resolved after the administration of corticoids and bronchodilators.

The chest radiograph was normal. The blood analyses were also normal, with total serum immunoglobulin E (Ig E) titers of $38 \mathrm{kU} / \mathrm{ml}$ and $2 \%$ eosinophils in the hemogram. Skin-prick tests with common pneumoallergens, as well as red cedar and iroko wood antigenic extracts, were negative. The pulmonary function studies were normal, with a forced vital capacity (FVC) of 6.11 $(117 \%)$, a forced expiratory volume in 1 second $\left(\mathrm{FEV}_{1}\right)$ of $5.21(123 \%)$, a $\mathrm{FEV}_{1} / \mathrm{FVC}$ ratio of $85 \%$, and negative bronchodilation testing. Peak expiratory flow testing performed by the patient at work and outside of work showed a variability of less than $10 \%$. Methacholine challenge testing was negative, with a methacholine concentration required to produce a $20 \%$ decrease in $\mathrm{FEV}_{1}\left(\mathrm{PC}_{20}\right)$ of $>16 \mathrm{mg} / \mathrm{ml}$. Nevertheless, during the test, the patient presented dysphonia and dyspnea at methacholine concentrations of $1 \mathrm{mg} / \mathrm{ml}$ and greater. The FEV ${ }_{1}$ did not decrease, but flattening of the inspiratory limb of the maximum flow-volume loop was observed, a finding consistent with variable extrathoracic upper-airway obstruction.

Finally, after giving his informed written consent, the patient underwent specific inhalation challenge according to the method proposed by Pepys \& Hutchcroft (13). Briefly, the patient tipped the wood dust tested (beech, pine, western red cedar, or iroko) from one tray to another 30 centimeters away from his face in a challenge booth with independent air extraction. During the specific inhalation challenge with iroko and western red cedar dust, the patient experienced dysphonia and chest tightness without a significant decrease in his $\mathrm{FEV}_{1}$, but, again, with a flattening of the inspiratory limb of the maximal flow-volume loop (figure 1). Fiberoptic rhinolaryngoscopy undertaken at this time revealed vocal cord dysfunction, with abnormal abduction of the true vocal cords during both inspiration and expiration. This condition had not been observed in the fiberoptic rhinolaryngoscopy performed before the specific inhalation challenge when the patient was asymptomatic. The symptoms induced during the specific inhalation challenge resolved spontaneously within 24 hours and were not observed during the subsequent specific inhalation challenges performed with beech and pine wood dust.

The patient was diagnosed with vocal cord dysfunction secondary to exposure to iroko and western red cedar wood dust and was referred to a speech therapist for training in control of the phonatory muscles during crises. He was advised to avoid exposure to the causative agents, but remained at the same workplace. He experienced occasional, moderately intense episodes, always related to contact with the two causal agents, but was able to self-limit them without medical support using the speech therapist's training.

\section{Case 2}

Case 2 involved a 35-year-old woman, a nonsmoker with no pathological history of interest. For the last 5 years she had been working in a company devoted to buying and selling products for in vitro diagnosis, together with 10 other persons. The workplace had little ventilation, and several laser printers and photocopiers were in constant use.

The patient was referred to our department because of an 18-month history of dyspnea, chest tightness, cough, and respiratory difficulty. The symptoms gradually progressed, and the patient had to go to a hospital emergency room on three occasions, where she was diagnosed with bronchial asthma.

The chest radiograph was normal. Blood test results were also normal, with total serum IgE titers 


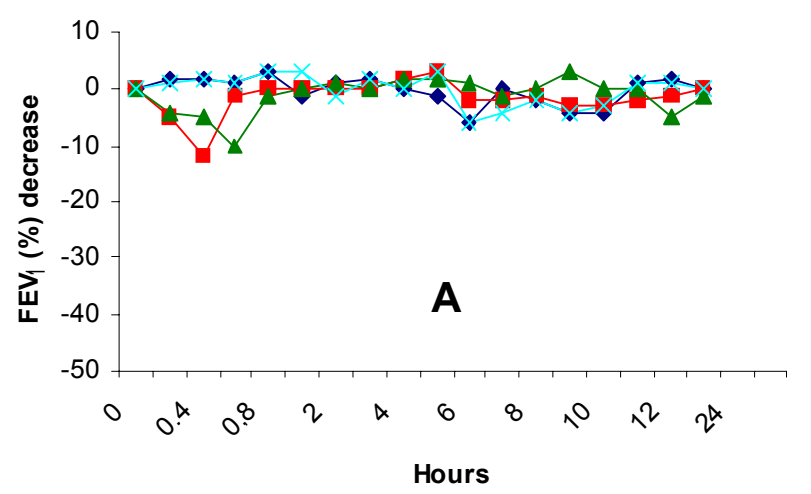

$\multimap$ Beech $\multimap-$ Western Red Cedar $\longleftarrow$ Iroko $\succ$ Pine
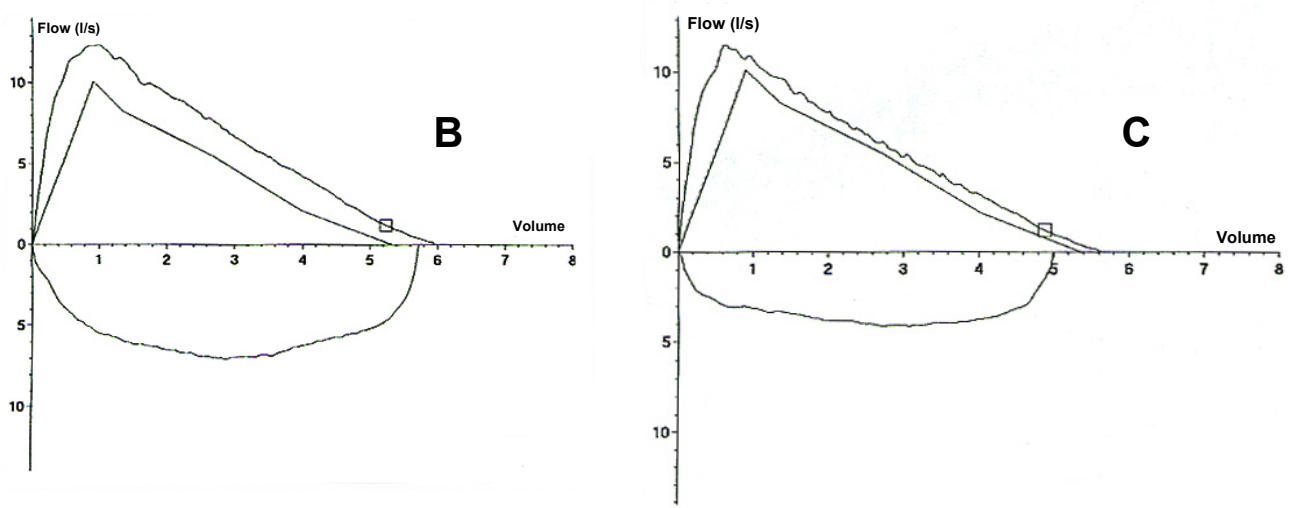

Figure 1. Results of the specific inhalation challenge with beech, pine, western red cedar and iroko ( $30 \mathrm{~g}$ per $150 \mathrm{~g}$ lactose) (A), the spirometry test before the specific inhalation challenge with iroko (B), and the spirometry test after the specific inahaltion challenge with iroko (C). The inspiratory limb is flattened, suggesting variable extrathoracic obstruction. The same pattern was found for the specific inahaltion challenge with western red cedar. $\left(\mathrm{FEV}_{1}=\right.$ forced expiratory volume in 1 second)

of $<10 \mathrm{kU} / \mathrm{ml}$ and $1 \%$ eosinophils in the hemogram. Skin-prick tests against common pneumoallergens were positive to Dermatophagoides pteronyssinus. The pulmonary function studies were normal, with an FVC of 4.21 (107\%), an $\mathrm{FEV}_{1}$ of 3.41 (97\%), an $\mathrm{FEV}_{1} / \mathrm{FVC}$ ratio of $79 \%$, and negative bronchodilation testing. During methacholine challenge, the patient experienced aphonia and inspiratory stridor. The test was interrupted at an inhaled concentration of $1 \mathrm{mg} / \mathrm{ml}$, when the $\mathrm{FEV}_{1}$ had decreased by $14 \%$ relative to the baseline value. A possible bronchial hyperresponse could not be ruled out. Flattening of the inspiratory limb of the maximum flow-volume loop was observed, a finding consistent with variable extrathoracic upper-airway obstruction.

The patient then underwent specific inhalation challenge to xerographic toner, according to the method described for case 1 . The dust contained in the cartridge was extracted and mixed with lactose for the test. During the specific inhalation challenge, she again experienced dysphonia and chest tightness. There was no significant $\mathrm{FEV}_{1}$ decrease, but flattening of the inspiratory limb of the maximum flow-volume loop was again observed (figure 2). The symptoms induced during the specific inhalation challenge resolved spontaneously within 24 hours and were not observed during the challenge with a placebo. Rhinolaryngoscopy could not be performed in this case because the patient did not grant permission for the test.

The patient was diagnosed with vocal cord dysfunction secondary to the inhalation of xerographic toner and was referred to a speech therapist for training in phonatory muscle control during crises. The patient changed jobs and thereby discontinued exposure to the causal agent. She had remained asymptomatic up to the time that this report was written.

\section{Discussion}

This is the first report to document the development of vocal cord dysfunction secondary to exposure to 

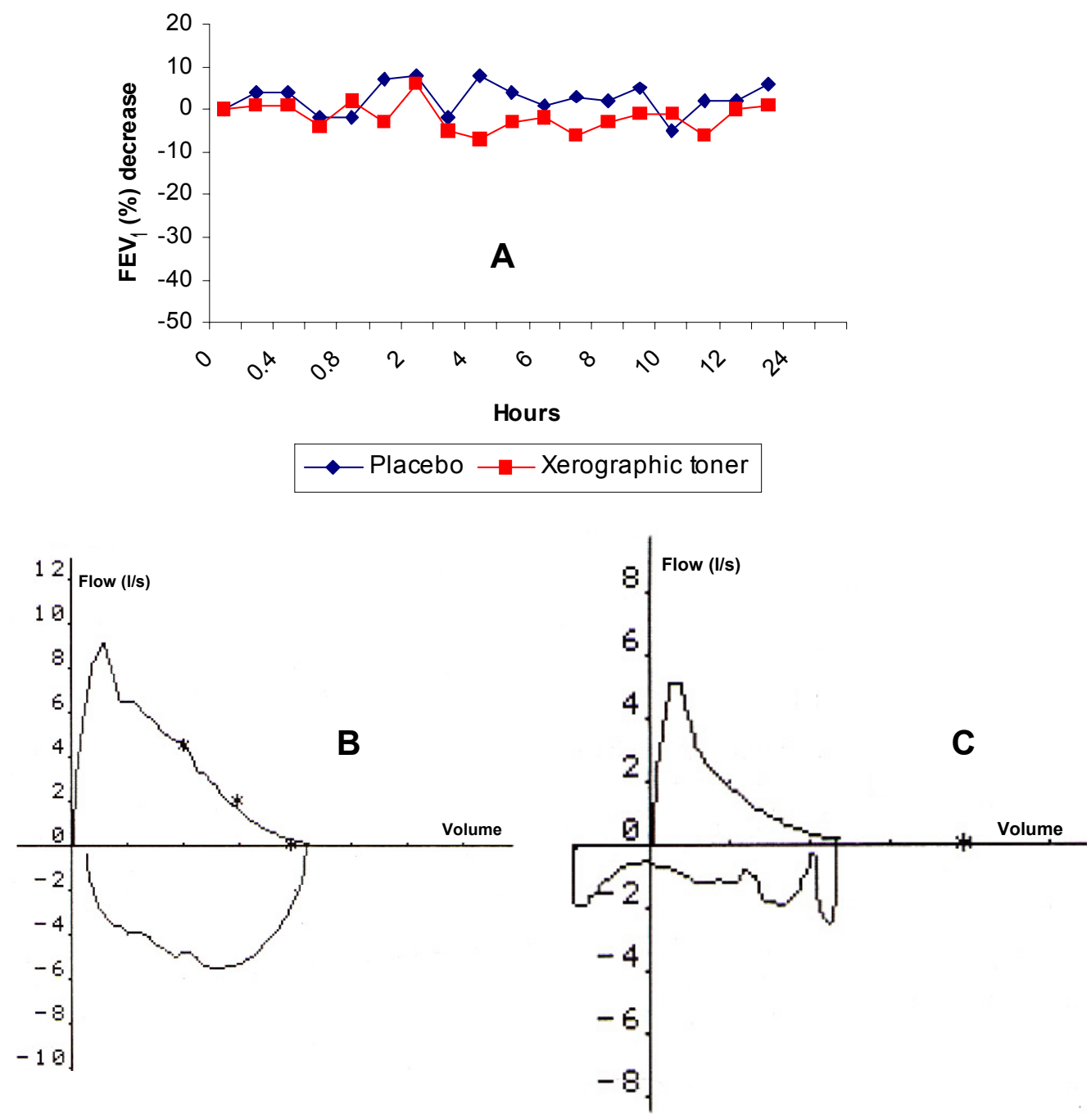

Figure 2. Results of the specific inhalation challenge with xerographic toner (10 g per $150 \mathrm{~g}$ lactose), and a placebo (150 g lactose) (A), the spirometry test before the specific inhalation challenge with xerographic toner (B), and the spirometry test after the specific inhalation challenge

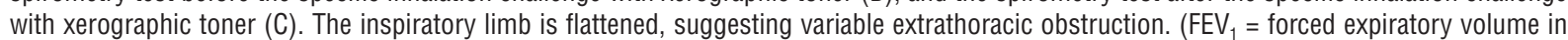
1 second)

iroko and western red cedar wood and to exposure to xerographic toner. All of these agents can also cause occupational asthma. The respiratory effects of red cedar on exposed workers are well recognized (14) Asthma due to this substance has been attributed to plicatic acid, a low-molecular-weight agent, although the pathologic mechanism remains unclear. Both immunologic and nonimmunologic mechanisms are likely to be involved. The immunologic mechanism implicated does not seem to be mediated by IgE antibodies (15), and recent studies have shown that $\mathrm{T}$ lymphocytes play an important role in the inflammatory response to this agent (16). Similar findings have been described in the few reported cases of occupational asthma due to iroko wood (17-21) and in a single case related to xerographic toner (22). According to these reports, a low-molecular-weight agent could be implicated in the development of asthma related to both of these agents. The mechanisms involved seem to be immunologic in nature and are not mediated by $\mathrm{Ig} \mathrm{E}$. The possibility of a nonimmunologic mechanism has not been reported. In our study, asthma was ruled out for the patients on the basis of low Ig E levels, a lack of variation in peak flow, a lack of bronchial hyperresponsiveness, and no evidence of a decrease in $\mathrm{FEV}_{1}$ in the specific inhalation challenge, which, however, elicited clinical symptoms of vocal cord dysfunction.

Two forms of vocal cord dysfunction have been described, an irritant and a nonirritant type (9). The small number of cases of irritant vocal cord dysfunction reported to date $(9,11,12)$ have met the following criteria proposed by Perkner et al (9): absence of prior vocal cord dysfunction or laryngeal disease, onset of symptoms after a single specific exposure to an irritant vapor, onset of symptoms within 24 hours after exposure, symptoms of wheezing, stridor, dyspnea, cough, abnormal direct rhinolaryngoscopy for vocal 
cord dysfunction with a challenge test, and exclusion of other vocal cord diseases.

The cases presented in this paper differ from the previously reported ones in that there was no increase in the dose of the causal agent involved. The patients had been working for years with sustained environmental exposure to the agents and did not mention exposure to higher doses at any time in their work history. Moreover, in contrast to most of the cases reported to date (9, 11,12 ), vocal cord dysfunction was produced in both patients by exposure to substances in the form of dust and not as vapor (9). The symptoms in our cases were elicited only in response to the agents described and never to other specific irritants. This fact suggests that there may be two types of irritant vocal cord dysfunction. In some of the reported cases, once the syndrome was induced, it could be reproduced by exposure to any irritant agent $(9,10)$. Nevertheless, in the two patients comprising our cases and in the cases reported by Huggins et al (11) and Gadi et al (12), the symptoms were triggered only with exposure to a specific agent and not with contact to other irritants.

The physiological mechanism that produces irritant vocal cord dysfunction is unknown. Our cases raise the possibility that several mechanisms may be implicated in the origin of this entity. We hypothesize that exposure to the causal substances may lead to histamine release in the airways, which would result in vocal cord dysfunction. It has been shown that high histamine levels can trigger this syndrome, even in normal persons (23). Plicatic acid is a known activator of the complement system via the classic pathway, which results in the generation of biologically active fragments, such as $\mathrm{C} 3 \mathrm{a}$ and $\mathrm{C} 5 \mathrm{a}$, that are able to induce histamine release from peripheral human basophils and mast cells (24). Histamine release has also been found in vitro in human lung tissue fragments exposed to western red cedar dust (25). Moreover, the symptoms were reproduced in our two patients when they underwent the methacoline challenge test. It has been suggested that this test can be useful for diagnosing vocal cord dysfunction $(26,27)$ because up to $60 \%$ of affected patients have findings suggestive of the diagnosis following methacholine challenge.

Finally, it should be remembered that psychiatric factors are important in this condition. Mental disorders, such as depression, anxiety, obsessive-compulsive disorder and borderline personality disorder have been associated with vocal cord dysfunction (5). Some authors have hypothesized that vocal cord dysfunction may be a conversion reaction in these patients (1). This factor cannot be excluded in our first case, but, in the second, an examination by a psychiatrist reasonably ruled out the presence of a mental disorder.

In conclusion, we have described two cases of irritant vocal cord dysfunction produced by agents that are known to cause occupational asthma through an immunologic mechanism. The specific mechanism by which these agents result in the symptoms of vocal cord dysfunction is unknown. Nevertheless, the clinical differences observed in these patients, as compared with previously reported cases, suggests that more than one pathophysiological mechanism may be involved.

\section{References}

1. Christopher KL, Wood RP, Eckert C, Blager FB, Raney RA, Souhrada KL. Vocal cord dysfunction presenting as asthma. N Engl J Med. 1983;308 (26):1566-70.

2. Wood RP, Milgrom H. Vocal cord dysfunction. J Allergy Clin Immunol. 1996;98(3):481-5.

3. Newman KB, Dubester SN. Vocal cord dysfunction: masquerader of asthma. Semin Respir Crit Care Med. 1994;15:162-7.

4. O'Connell MA, Sklarew PR, Goodman DL. Spectrum of presentation of paradoxical vocal cord motion in ambulatory patients. Ann Allergy Asthma Immunol. 1995;74(4):341-4.

5. Newman KB, Mason UG, Schmaling KB. Clinical features of vocal cord dysfunction. Am J Respir Crit Care Med. 1995;152(4 Pt 1):1382-6.

6. McFadden ER Jr, Zawadski DK. Vocal cord dysfuction masquerading as exercise-induced asthma: a physiologic cause for "choking" during athletic activities. Am J Respir Crit Care Med. 1996;153(3):942-7.

7. Rundell KW, Spiering BA. Inspiratory stridor in elite athletes. Chest. 2003;123(2):468-74.

8. Wilson JJ, Wilson EM. Practical management: vocal cord dysfunction in athletes. Clin J Sport Med. 2006;16(4):357-60.

9. Perkner JJ, Fennelly KP, Balkissoon R, Bartelson BB, Ruttenber AJ, Wood RP, et al. Irritant-associated vocal cord dysfunction. J Occup Environ Med. 1998(2);40:136-43.

10. Balkissoon R. Occupational upper airway disease. Clin Chest Med. 2002;23(4):717-25.

11. Huggins JT, Kaplan A, Martin-Harris B, Sahn SA. Eucalyptus as a specific irritant causing vocal cord dysfunction. Ann Allergy Asthma Immunol. 2004;93(3):299-303.

12. Galdi E, Perfetti L, Pagella F, Bertino G, Ferrari M, Moscato G. Irritant vocal cord dysfunction at first misdiagnosed as reactive airway dysfunction syndrome [case report]. Scand J Work Environ Health. 2005;31(3):224-6.

13. Pepys J, Hutchcroft BJ. Bronchial provocation test in aetiology diagnosis and analysis of asthma. Am Rev Respir Dis. 1975;112(6):829-59.

14. Chang-Yeung M. Western red cedar (Thuja plicata) and other wood dust. In: Bernstein IL; Chang-Yeung M, Malo JL, Bernstein D, editors. Asthma in the work place. 2nd ed. New York (NY): Marcel Dekker, Inc; 1999. p 543-63.

15. Frew A, Chan H, Dryden P, Salari S, Lam S, Chang-Yeung M. Immunologic studies of the mechanisms of occupational asthma caused by western red cedar. J Allergy Clin Immunol. 1993;92(3):466-78.

16. Frew A, Chan H, Lam S, Chang-Yeung M. Bronchial inflammation in occupational asthma due to western red cedar. Am J Respir Crit Care Med. 1994;151(2 Pt 1):340-4.

17. Pickering CAC, Batten JC, Pepys J. Asthma due to inhaled wood dust western red cedar and iroko. Clin Allergy. 1972;2(2):213-8. 
18. Azofra J, Olaguibel JM. Occupational asthma caused by iroko wood. Allergy. 1989;44(2):156-8.

19. De Zotti R, Gubian F. Asthma and rhinitis in wooding workers. Allergy Asthma Proc. 1996;17(4):199-203.

20. Ricciardi L, Fedele R, Saitta S, Tigano V, Mazzeo L, Fogliani $\mathrm{O}$, et al. Occupational asthma due to exposure to iroko wood dust. Ann Allergy Asthma Immunol. 2003;91(4):393-7.

21. Casas X, Riu E, Rivera M, Monso E. Asma ocupacional por iroko [Occupational asthma due to iroko]. Med Clin (Barc). 2003;120(6):238-9.

22. Wittczak T, Walusiak J, Rula U, Palezynski C. Occupational asthma and allergic rhinitis due to xerographic toner. Allergy. 2003;58(9):957.

23. Balkissoon R. Occupational upper airway disease. Clin Chest Med. 2002;23(4):717-25.
24. Chang-Yeung M, Giclas P, Henson P. Activation of the complement by plicatic acid, the chemical compound responsible for asthma due to western red cedar (Thuja plicata). J Allergy Clin Immunol. 1980;65(5):333-7.

25. Evand E, Nicholls PJ. Histamine release by western red cedar (Thuja plicata) from lung tissue in vitro. J Ind Med. 1974;31(1):28-30

26. Perkins P, Morris M. Vocal cord dysfunction induced by methacholine challenge testing. Chest. 2002;122(6):1988-93.

27. Crapo RO, Casaburi R, Coates AL, Enright PL, Hankinson JL, Irvin CG, et al. Guidelines for methacholine and exercise challenge testing-1999. Am J Respir Crit Care Med. 2000;161(1): 309-29.

Received for publication: 17 August 2006 